\title{
Effects of drying temperature on the chemical and physical properties of Musa acuminata Colla (AAA Group) leaves.
}

\begin{abstract}
Typically, banana trees are cut once the fruit has been harvested; however, other parts of the banana tree, particularly the leaves, might have other potential uses. Nevertheless, few studies have focused on banana leaves. This work aims to provide information about the effects of different drying temperatures on the antioxidant activity, total phenolic content and physical properties of banana leaves (Musa acuminata Colla (AAA Group)). Leaves were dried at different temperatures $\left(40{ }^{\circ} \mathrm{C}, 50{ }^{\circ} \mathrm{C}\right.$ or $\left.60{ }^{\circ} \mathrm{C}\right)$ using a cabinet dryer with an airflow of $2 \mathrm{~m} / \mathrm{s}$. Dried and fresh leaves were analysed for their moisture content, water activity, $\mathrm{pH}$, colour analysis and rehydration index. The 2,2-diphenyl-1-picrylhydrazyl (DPPH) and FolinCiocalteau methods were used to determine the scavenging activity (IC50) and total phenolic content of the fresh and dried leaves extracts, respectively. The results reveal that the drying temperature significantly affects selected properties of banana leaves and $50{ }^{\circ} \mathrm{C}$ is proposed as the appropriate drying temperature.
\end{abstract}

Keyword: Banana leaves; Drying; Physical properties; Antioxidant activity; Total phenolic content. 